\title{
(6) OPEN ACCESS \\ Management of critical illness with non-invasive ventilation by an Australian HEMS
}

\author{
Andrew R Coggins, ${ }^{1,2}$ Erin N Cummins, ${ }^{1}$ Brian Burns ${ }^{2,3}$
}

${ }^{1}$ Department of Emergency Medicine, Westmead Hospital, Sydney, New South Wales, Australia

${ }^{2}$ Discipline of Emergency Medicine, The University of Sydney, Sydney, New South Wales, Australia

${ }^{3}$ Ambulance Service of New South Wales, Greater Sydney Area HEMS, Sydney, New

South Wales, Australia

\section{Correspondence to}

Dr Andrew Coggins, Department of Emergency Medicine, Westmead Emergency, Hawkesbury Rd, Sydney, NSW 2145, Australia; andrewrcoggins@gmail.com

Received 14 September 2015 Revised 8 June 2016 Accepted 10 June 2016 Published Online First 1 July 2016

\begin{abstract}
Background Non-invasive ventilation (NIV) therapy is widely used for the management of acute respiratory failure. The objective of this study was to investigate the current use of NIV during interhospital retrievals in an Australian physician-led aeromedical service.

Methods We reviewed patients receiving NIV during interhospital retrieval at the Greater Sydney Area Helicopter Medical Services (GSA-HEMS) over a 14-month period. The main objectives were to describe the number of retrievals using NIV, the need for intubation in NIV patients and the effect of the therapy on mission duration.
\end{abstract}

Results Over the study period, 3018 missions were reported; 106 cases (3.51\%) involved administration of NIV therapy during the retrieval. The most common indication for NIV was pneumonia (34.0\%). 86/106 patients received a successful trial of NIV therapy prior to interhospital transfer. 58 patients were transferred on NIV, while 28 patients had NIV removed during transport. None of these 86 patients required intubation or died, although $17 / 86$ ultimately required intubation within 24 hours at the receiving centre. 20/106 patients required intubation at the referring hospital after a failed trial of NIV therapy. NIV was successfully used in all available transport platforms including rotary wing. Patients receiving NIV were found to have prolonged mission durations compared with other GSA-HEMS patients (222.5 vs $193 \mathrm{~min}$ ). This increase in mission duration was largely attributable to NIV failure, resulting in a need for Rapid Sequence Intubation at the referring hospital.

Conclusions With careful patient selection, the use of interhospital NIV is feasible and appears to be safe in a retrieval system with care provided by a critical care physician.

\section{BACKGROUND}

Non-invasive positive pressure ventilation (NIV) is a widely used therapy in the management of acute respiratory emergencies including acute hypoxic and hypercapnoeic respiratory failure. ${ }^{1}$ NIV is also an established treatment of congestive heart failure (CHF), pneumonia and chronic obstructive pulmonary disease (COPD). ${ }^{2}{ }^{3}$

The use of NIV in the prehospital environment has been associated with improvement in vital signs and a reduced need for endotracheal intubation. ${ }^{45}$ Recent systematic reviews of the literature have supported the use of NIV in the prehospital setting. ${ }^{67}$ Out-of-hospital administration of NIV appears to be a promising therapy for respiratory distress with short transport times. ${ }^{8}$ However, there is limited reporting beyond studies of paediatric populations

\section{Key messages}

What is already known on this subject?

- Non-invasive ventilation (NIV) is an established evidence-based therapy in the management of acute respiratory failure in the hospital setting.

- There is an emerging evidence base for the use of NIV in the urban prehospital setting.

- To date, there has been minimal reporting of the use of NIV in critically unwell patients requiring interhospital transfer.

\section{What might this study add?}

- In this Australian observational study of interhospital NIV, none of the patients required intubation during transport or died during the interhospital retrieval. Seventeen patients required intubation and mechanical ventilation at the receiving hospital within 24 hours.

- NIV appears to be a safe management option in a select number of patients requiring interhospital transfer.

- Judicious patient selection and senior physician supervision are important contributors to patient safety when using NIV for interhospital transfer.

of NIV use in patients requiring longer interhospital transfers. ${ }^{9}{ }^{10}$ A recent case series has suggested that adult interhospital NIV may be associated with a risk of patient deterioration. ${ }^{11}$ Studies in other retrieval services with larger populations are therefore necessary. ${ }^{12}$

The overall aim of this study was to investigate the current use of NIV in critically unwell adults undergoing retrieval by an Australian physician-led aeromedical service. ${ }^{12}$ Greater Sydney Area Helicopter Medical Services (GSA-HEMS) provides prehospital and interhospital missions to a population of $>7$ million in an area $>800000 \mathrm{~km}^{2} .{ }^{13}$ The service operates across three bases and uses all retrieval platforms (road, rotary and fixed wing). The medical team is completed by flight nurses for fixed wing and paramedics for road or rotary wing missions.

\section{MATERIALS AND METHODS \\ Study interventions}

GSA-HEMS patients in whom NIV is considered appropriate are given a trial of NIV prior to interhospital transfer. A successful trial of NIV is determined by the gestalt of the treating clinician based on various parameters including clinical observations, $\mathrm{ABGs}$ and treatment tolerance. NIV is
Cummins EN, Burns B.

811

Coggins AR, et al. Emerg Med J 2016;33:807-811. doi:10.1136/emermed-2015-205377 
performed using the Oxylog $3000+$ transport ventilator (Draeger, Germany). ${ }^{14}$ Manufacturer's guidelines exist for providing NIV using the Oxylog $3000+$ and are followed by the retrieval teams. Bilevel positive airway pressure (BiPAP) and continuous positive airway pressure (CPAP) modes are both available at the discretion of the treating physician. Titration of NIV is carried out by adjustment to the standard ventilation parameters. Oxygen availability in all transport platforms (ie, road, fixed wing and rotary wing) includes two standard ' $D$ ' cylinders with a capacity of approximately 3200 L. NIV is provided using an appropriately sized mask with head straps.

\section{Patient selection}

Study protocols were examined and approved by the Western Sydney local health district (WSLHD) ethics committee. The GSA-HEMS electronic medical record (EMR) was searched for patients transported between 1 March 2012 and 30 April 2013. We identified patients receiving NIV from the 'tick box' charting option indicating NIV use and an electronic search for the terms: 'CPAP', 'NIV' and 'BiPAP'. All extracted cases were examined according to predefined inclusion and exclusion criteria. ${ }^{15}$ Criteria for inclusion in the study were definite evidence in the EMR of NIV use by the retrieval team. The included patients were divided into three groups. Group 1 were transported on NIV therapy. Group 2 were given NIV by the retrieval team but required intubation prior to transport. Group 3 initially received NIV at the referring institution but not during transport. Exclusion criteria included patients who died or received palliative care prior retrieval team arrival, intubation required prior to mission tasking, paediatric age (defined as $<16$ years) and cases with no evidence of NIV use. A second reviewer checked all the cases to ensure inclusions, exclusions and groupings were appropriate and found no errors.

A single investigator examined the EMR and data were collected using an extraction sheet approved by the WSLHD research committee. ${ }^{15}$ Data entry and accession numbers were then crosschecked for errors by a second independent reviewer. Standardised 24-hour postmission phone calls were made to receiving hospitals for all transported patients during the study period. Trained GSA-HEMS staff carried out these calls and added the data to the EMR. Medical records and data from telephone follow-up were complete for all patients in the study and no cases were lost to follow-up.

\section{Outcomes of interest}

The main objectives of this study were to describe the number of retrievals using NIV, the need for intubation in NIV patients and the effect of the therapy on mission duration. Descriptive statistics (means, medians, percentages) were used to examine the characteristics of patients receiving NIV. Descriptive data collected included the level of experience of the physician, patient demographics, logistics, mission timings, as well as clinical variables including vital signs. We determined the median mission timings for patients who received NIV based on the three groups described above. These mission timings were compared with the timings of all other missions carried out by the GSA-HEMS service.

Mission timings for the retrieval service were defined as follows:

- Total mission time: departure from base until return to base.

- Transit time: departure from referring hospital to arrival at the receiving hospital.

- Treatment time: total patient contact time at the referring centre (ie, arrival at patient to departure with patient).
Mission timing data were statistically evaluated using Stata V.11 (Stata, USA). The Wilcoxon ranked-sum test was used comparative analyses. The hypothesis tested was that the use of NIV would significantly increase the mission duration. Comparative statistical analysis was not performed on other results due to the high likelihood of confounders.

\section{RESULTS}

From a total of 3018 missions carried out over the 14-month period, 106 patients were administered NIV by the retrieval service (figure 1). Of the 106 patients, 28 were administered NIV but had it removed for transport; 20 failed a trial of NIV therapy and were intubated and 58 were transported using NIV. In the 86 patients where a trial of NIV was used successfully, $0 / 86$ required intubation during transport. No patient that received NIV from the retrieval teams died in transit or within the 24-hour follow-up period.

Median age of the patients was 63, with a slight predominance of males. Vital signs were recorded in all patients and reflected the characteristic critical care needs of the GSA-HEMS population (table 1). The most common provisional diagnosis (table 2) was pneumonia (34.0\%). Patients with cardiogenic shock (CS) and CHF suffered lower rates of failed NIV during retrieval $(4 / 25)$ but had the highest rate of intubation within 24 hours at the receiving centre (8/21 intubated by 24 hours). $19.8 \%(17 / 86)$ of the non-intubated patients ultimately required intubation within 24 hours at the receiving hospital.

Subsequent examination of the individual records of the 17 patients intubated within 24 hours showed 4/17 patients had septic shock with end-organ dysfunction. In these cases, intubation at the receiving centre was required due to a predictable clinical course. Also, 8/17 patients had a clinical picture consistent with CS. This picture was associated with ischaemic

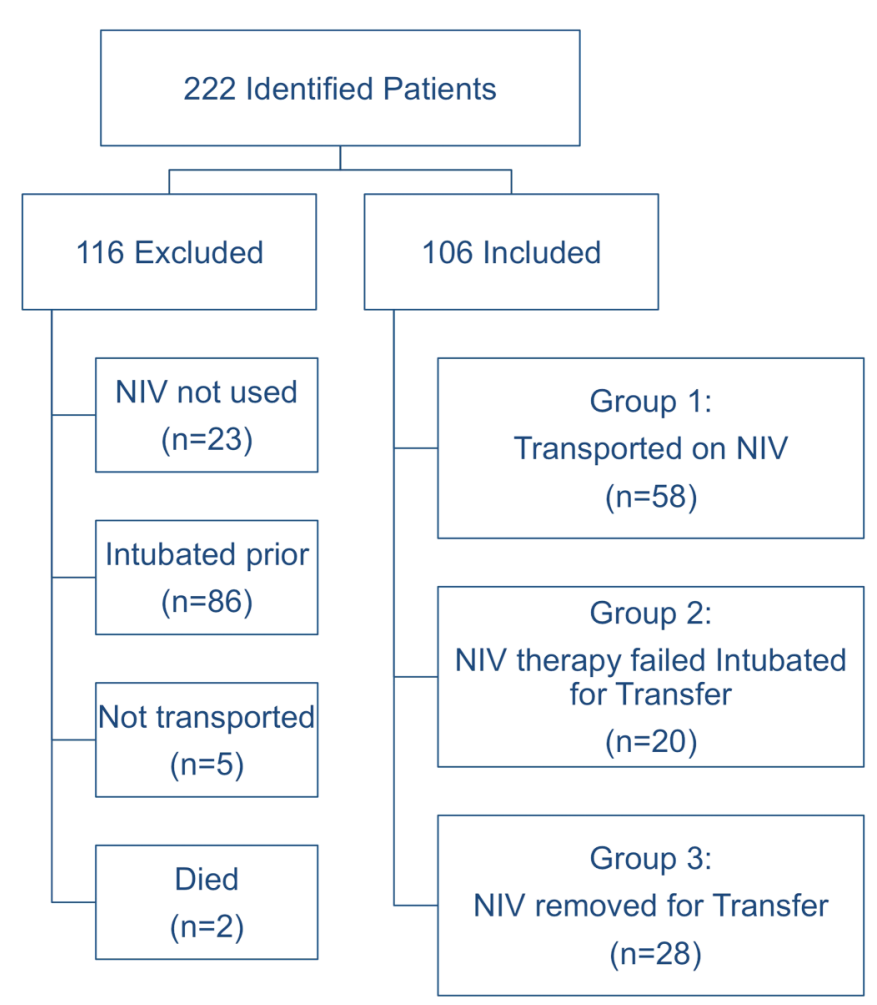

Figure 1 Flow diagram: included and excluded cases. NIV, non-invasive ventilation. 
Table 1 Overview of patients receiving non-invasive ventilation (NIV)

\begin{tabular}{|c|c|c|c|c|}
\hline Characteristic & $\begin{array}{l}\text { All retrieval NIV } \\
\text { patients }(n=106)\end{array}$ & $\begin{array}{l}\text { NIV for transport } \\
(n=58)\end{array}$ & $\begin{array}{l}\text { Failed a trial of } \\
\text { NIV }(n=20)\end{array}$ & $\begin{array}{l}\text { NIV removed for transport } \\
(n=28)\end{array}$ \\
\hline Median age & $63(14-85)$ & $62(14-85)$ & $62.5(20-83)$ & $64(18-82)$ \\
\hline Doctor grade-consultant & 34 & 19 & 3 & 12 \\
\hline Doctor grade-registrar & 72 & 39 & 17 & 16 \\
\hline Female gender & 47 & 23 & 10 & 14 \\
\hline Male gender & 59 & 35 & 10 & 14 \\
\hline Median $\mathrm{O}_{2}$ saturations (start) & $97(61-100)$ & $96(61-100)$ & $96(84-100)$ & $97(80-100)$ \\
\hline Median $\mathrm{O}_{2}$ saturations (end) & $98(83-100)$ & $98(83-100)$ & $98(90-100)$ & $97(84-100)$ \\
\hline Median systolic BP (start) & $130(60-270)$ & $135(80-270)$ & 135 (80-195) & $113(60-190)$ \\
\hline Median systolic BP (end) & $126(95-200)$ & $129.5(98-200)$ & $130(100-180)$ & $117(95-150)$ \\
\hline Median RR (start) & $26(12-45)$ & $25.5(12-42)$ & $26.5(13-45)$ & $25.5(18-39)$ \\
\hline Median RR (end) & $22(12-38)$ & $24.5(12-38)$ & $15(12-28)$ & $25(14-35)$ \\
\hline Median pulse rate (start) & $95(36-150)$ & $91(36-140)$ & $110.5(66-150)$ & $92.5(50-140)$ \\
\hline Median pulse rate (end) & $94(50-150)$ & $90(51-140)$ & $101(58-135)$ & $90(50-140)$ \\
\hline Inotropic support required at 24 hours & $13(12.3 \%)$ & $6(10.3 \%)$ & $2(10 \%)$ & $5(17.9 \%)$ \\
\hline Death in mission or at 24 hours & $0(0 \%)$ & $0(0 \%)$ & $0(0 \%)$ & $0(0 \%)$ \\
\hline ECMO or IABP at 24 hours & $2(1.89 \%)$ & $1(1.72 \%)$ & $1(5 \%)$ & $0(0 \%)$ \\
\hline Intubation required at 24 hours & $17(19.8 \%)$ & $12(20.7 \%)$ & $\mathrm{N} / \mathrm{A}$ & $5(17.8 \%)$ \\
\hline
\end{tabular}

cardiomyopathy or the valvular disease associated with rheumatic fever (common in Australian indigenous communities). With hindsight, a portion of these patients had a predictable need for invasive ventilation. However, three of the cases were not intubated due to the improvement in vital signs associated with NIV and a perceived high risk of intubation for CS in a remote setting. Also, 5/17 patients had hypoxic respiratory failure associated with COPD exacerbation. In these cases, intubation was avoided due to the risk of ventilator-associated pneumonia and likelihood of prolonged mechanical ventilation in the receiving centre after intubation.

Consultants used NIV in 34/1105 (3.1\%) of overall missions compared with $72 / 1908(3.8 \%)$ by registrars (doctors in training). Lower rates of therapy failure were observed in the presence of a consultant (3/34 vs 17/72).

Transport platforms used included fixed wing, rotary wing, road ambulance and the bariatric 'multipurpose vehicle' (MPV). As a proportion of all missions, NIV use was reported in 59/ $1189(4.96 \%)$ of road, 30/1512 (1.98\%) of rotary wing, 11/278 (3.96\%) of fixed wing and 7/39 (17.95\%) of MPV (bariatric) transfers.

Overall mission duration was longer in patients receiving NIV, although time in transit was similar (table 3). Compared with patients who received a successful trial of NIV, patients who required intubation after a failed trial of therapy had significantly longer treatment times and overall duration of mission but a similar time in transit (table 4 ).

\section{DISCUSSION}

The use of NIV in this retrieval service reflects the diverse clinical and geographical requirements of the Australian population. NIV cases account for $>3 \%$ of the overall GSA-HEMS service workload. Patients in this study were found to have received NIV at various points including for stabilisation at the referring hospital, prior to a rapid sequence intubation (RSI) and for ongoing therapy during transport.

Within the limitations of this observational study, the current use of NIV appears to be safe in the interhospital setting. No patients required intubation in transit $(0 / 86)$ and there were no deaths during transfer or within 24 hours. The patients transported using NIV had a high level of critical care requirements and case diversity in terms of diagnosis and geographical location.

Our study appears to conflict with evidence from a previous study that suggests a risk of deterioration in transit with interhospital NIV. An Australian case series looking at interhospital NIV reported 3/29 patients had cardiorespiratory collapse during transport. ${ }^{10}$ In contrast, the evidence from this study suggests NIV can be used successfully on road, fixed wing and rotary wing platforms. The anecdotal experience of our retrieval physicians suggests a high degree of vigilance and an awareness of the limitations of NIV therapy are necessary for success. Maintaining patient safety also depends on a supportive governance structure (ie, consultation with experienced on-call specialists) and judicious patient selection. ${ }^{16}$ Extensive training

Table 2 Diagnosis of patients and need for intubation $(n=106)$

\begin{tabular}{|c|c|c|c|c|c|c|c|}
\hline Variable & Asthma & Cardiogenic & Sepsis & COPD & Pneumonia & Other respiratory & Total \\
\hline All NIV cases (n) & 5 & 29 & 1 & 28 & 36 & 7 & 106 \\
\hline Failed NIV cases (n) & 2 & 4 & 0 & 7 & 7 & 0 & 20 \\
\hline Transported cases (n) & 3 & 25 & 1 & 21 & 29 & 7 & 86 \\
\hline Intubated by 24 hours (n) & 0 & 8 & 1 & 2 & 6 & 0 & 17 \\
\hline
\end{tabular}

COPD, chronic obstructive pulmonary disease; NIV, non-invasive ventilation. 
Table 3 Mission timings

\section{Timings (min)}

Median (IQR)

All NIV cases $(n=106)$

All other missions $(n=2912)$

$\begin{array}{lcc}\text { Total mission time } & 225.5(160-324) & 193(127-256) \\ \text { Treatment time } & 50(30-87) & 40(21-53) \\ \text { Transit time } & 39.5(30-62) & 40(20-54)\end{array}$

NIV, non-invasive ventilation.

Table 4 Mission timings of non-invasive ventilation (NIV) patients requiring intubation

\begin{tabular}{lccc}
\hline Timings $(\mathrm{min})$ & $\begin{array}{l}\text { Not intubated } \\
\text { during retrieval } \\
(\mathbf{n}=\mathbf{8 6})\end{array}$ & $\begin{array}{l}\text { Intubated at } \\
\text { referring centre } \\
(\mathbf{n}=\mathbf{2 0})\end{array}$ & $\begin{array}{l}\mathbf{p} \text { Value } \\
\text { (Wilcoxon } \\
\text { ranked-sum) }\end{array}$ \\
\hline Total mission time & 205 & 298 & 0.002 \\
Treatment time & 43 & 100 & 0.0001 \\
Transit time & 35 & 47.5 & 0.06 \\
\hline
\end{tabular}

including in situ simulation and crew resource management exercises may also contribute to the successful use of NIV.

The durations of retrieval missions reported in this study (table 3) may reflect both geographical distance and case complexity. In addition, it appears that failure of NIV therapy is associated with increased mission and treatment times (table 4). The increased mission durations observed with NIV therapy could be attributed to the practice of 'trialling NIV' at the referring centre. This trial is carried out using the retrieval service ventilator rather than the local hospital device. The retrieval team then assesses the patient for comfort, fatigue and work of breathing prior to transport. The practice of selecting interventions in the context of individual needs and logistical concerns is supported by the wider prehospital literature. ${ }^{17}$

While no patients deteriorated during transport to the point of requiring intubation, there are important limitations to consider when using interhospital NIV. While RSI is possible in-flight, ${ }^{18}$ it is avoided where possible due to logistical difficulties and the lower success rates reported. ${ }^{19}$ The current selective use of interhospital NIV reflects a careful balance of the benefits of the therapy versus the risk of deterioration during transport. From this study and wider anecdotal experience, we have identified four major factors to consider when using NIV. These four factors are equipment factors, aviation considerations, patient factors and oxygen consumption:

- Patient factors-Patient factors such as comorbidities, mask fit, air travel anxiety and motion sickness should all be considered. $^{2021}$ Successful NIV use is dependent on a trial of tolerability and patient cooperation. Careful patient selection is essential in order to avoid adverse outcomes. ${ }^{10}$ Selection should be based on local protocols and senior advice.

- Equipment factors-Not all transport ventilators provide adequate and effective NIV. The patient may have to work harder to trigger an assisted breath than with devices designed to provide NIV as their primary function.

- Oxygen consumption-Oxygen flow can be in the range of 9-35 L/min with the Oxylog 3000+. ${ }^{14}$ Operation time can be estimated (medical gas supply (L)/MV+0.5 (L/min)). Mask air leak can cause increased flow and therefore decreased operation time. A recent small case series of NIV transport showed a mean oxygen consumption of $232.2 \mathrm{~L}^{10}$
- Aviation considerations-Aviation factors such as transport distance, vehicle space, weight restrictions and patient access should always be considered. In this study, six patients were transported by rotary wing with ongoing NIV without complication.

Adequate mission planning addressing the four factors listed above are likely to make selective use of NIV feasible in many jurisdictions. Common indications observed for interhospital NIV appear to be similar to those described in the literature for ED patients. ${ }^{22}$ Furthermore, many of the factors associated with NIV failure in this interhospital study appeared to be similar to those encountered in the hospital setting. ${ }^{23}$

\section{STUDY LIMITATIONS}

The study reports on a limited number of patients in a single retrieval service, so caution must be used in extrapolating the results to other locations. The outcome data, while complete and appropriate for the study question, were limited to short-term follow-up. Additionally, there are potential intrinsic methodological issues associated with retrospective data collection and analysis. ${ }^{15}$ The extraction of data was performed by a single investigator who was not blinded to the intent of the study. There is potential for observer and measurement biases. However, no errors were found when a second independent reviewer checked appropriate data entry, inclusions and patient groupings.

\section{FUTURE DIRECTIONS}

The cohort described in this study had a high level of critical care needs including vasopressors and intubation within 24 hours of arrival to the receiving facility. Optimising the selection of patients suitable for NIV therapy based on clinical criteria is a potential area for further investigation. While not powered for statistical analysis, this study suggests an apparent trend of CHF patients tolerating NIV well during transport but being more likely to require intubation and inotropes at the receiving centre. This finding could be an area for further study. ABG measurements were often taken in NIV patients but serial results were not available for the majority of cases. Given the importance of ABGs in decision-making around NIV therapy, this is also an important consideration for future interhospital NIV studies.

\section{CONCLUSIONS}

This study suggests NIV is a useful treatment in a significant proportion of critically unwell patients requiring intrahospital transfer. The immediate benefits (eg, haemodynamic and respiratory) and latent benefits (eg, reduced intensive care stay and ventilator-associated pneumonia) should be weighed against the risk of deterioration during transport. When there is uncertainty about the risk of transfer, a trial of NIV therapy in the referring hospital and consultation with experienced colleagues should be undertaken. We conclude that modern integrated aeromedical services should consider the development of local operating procedures for the use of interhospital NIV.

Correction notice Since this paper was first published online table 3 has been modified. The transit time data in the 'All NIV cases $(n=106)$ ' column has been updated. It now reads 39.5 (30-62).

Twitter Follow Andrew Coggins at @coggi33

Contributors $A R C$ and $B B$ conceived the study. ARC extracted data from the electronic medical record, which was crosschecked by ENC and BB. BB and ARC performed the data analysis. All authors contributed to and have approved the final manuscript.

Competing interests None declared. 
Ethics approval Westmead Hospital Ethics Committee.

Provenance and peer review Not commissioned; externally peer reviewed.

Data sharing statement Data are provided in full in the results section of this paper. Non-digital materials supporting this study are stored securely by the corresponding author at the University of Sydney. Data are available from AC upon request.

Open Access This is an Open Access article distributed in accordance with the Creative Commons Attribution Non Commercial (CC BY-NC 4.0) license, which permits others to distribute, remix, adapt, build upon this work non-commercially, and license their derivative works on different terms, provided the original work is properly cited and the use is non-commercial. See: http://creativecommons.org/ licenses/by-nc/4.0/

\section{REFERENCES}

1 Hill NS, Brennan J, Garpestad E. Non-invasive ventilation in acute respiratory failure. Crit Care Med 2007;35:2402-7.

2 Vital FM, Saconato H, Ladeira MT, et al. Non-invasive positive pressure ventilation (CPAP or bi-level NPPV) for cardiogenic pulmonary edema. Cochrane Database Syst Rev 2008;(3):CD005351.

3 Ram FS, Picot J, Lightowler J, et al. Non-invasive positive pressure ventilation for treatment of respiratory failure due to exacerbations of chronic obstructive pulmonary disease. Cochrane Database Syst Rev 2004;(3):CD004104.

4 Taylor DM, Bernard SA, Masci K, et al. Prehospital non-invasive ventilation: a viable treatment option in the urban setting. Prehosp Emerg Care 2008;12:42-5.

5 Dib JE, Matin SA, Luckert A. Prehospital use of continuous positive airway pressure for acute severe congestive heart failure. J Emerg Med 2012;42:553-8.

6 Williams TA, Finn J, Perkins GD, et al. Prehospital continuous positive airway pressure for acute respiratory failure: a systematic review and meta-analysis. Prehosp Emerg Care 2013;17:261-73.

7 Goodacre $S$. Pre-hospital non-invasive ventilation for acute respiratory failure: a systematic review and network meta analysis. Emerg Med J 2014;31:778.

8 Mal S, McLeod S, lansavichene A, et al. Effect of out-of-Hospital non-invasive positive-pressure support ventilation in adult patients with severe respiratory distress: a systematic review and meta-analysis. Ann Emerg Med 2014;63:600-7.

9 Baird JS, Spiegelman JB, Prianti R, et al. Noninvasive ventilation during pediatric interhospital ground transport. Prehosp Emerg Care 2009;13:198-202.
10 Garrote Jl, Aylagas D, Gutierrez JM, et al. Noninvasive mechanical ventilation in helicopter emergency medical services saves time and oxygen and improves patient and mission safety: a pilot study. Air Med J 2015;34:218-22.

11 Le Cong M, Robertson A. A 3-year retrospective audit of the use of noninvasive positive pressure ventilation via the $0 x y \log 3000$ transport ventilator during air medical retrievals. Air Med J 2013:32:126-8.

12 Greater Sydney Area Helicopter Medical Service (GSA-HEMS). Ambulance Service of New South Wales. http://www.ambulance.nsw.gov.au/about-us/aeromedical.html (accessed 21 Dec 2014).

13 Australian Bureau of Statistics: Population Demographics. 2011. http://www.abs. gov.au/ausstats (accessed 16 Dec 2014)

14 Draeger Germany. Oxylog 3000 plus (Manual). http://www.draeger.net/media/10/ 08/29/10082917/9066099_0xylog_3000_plus_EN_170510.pdf (accessed 20 Jan 2015).

15 Gearing R, Mian I, Barber J, et al. A methodology for conducting retrospective chart review research in child and adolescent psychiatry. I Can Acad Child Adolesc Psychiatry 2006;15:126-34.

16 Hearns S, Shirley PJ. Retrieval medicine: a review and guide for UK practitioners. Part 2: safety in patient retrieval systems. Emerg Med J 2006;23:943-7.

17 Van Schuppen H, Bierens J. Understanding the prehospital physician controversy. Step 1: comparing competencies of ambulance nurses and prehospital physicians. Eur J Emerg Med 2011;18:322-7.

18 Slater EA, Weiss Steven J, Ernst Amy A, et al. Pre-flight versus en route success and complications of rapid sequence intubation in an air medical service. J Trauma 1998;45:588-92.

19 McIntosh SE, Swanson ER, McKeone A, et al. Location of airway management in ai medical transport. Prehosp Emerg Care 2008;12:438-42.

20 Harper P. Personal experience of aeromedical evacuation of patients in the Balkans. BrJ Nurs 2005;14:202-4.

21 Singh JM, MacDonald RD, Bronskill SE, et al. Incidence and predictors of critical events during urgent air-medical transport. CMAJ 2009;181:579-84.

22 Rose L, Gerdtz MF. Non-invasive mechanical ventilation in Australian emergency departments: a prospective observational cohort study. Int I Nurs Stud 2009;46:617-23.

23 Agarwal R, Gupta R, Aggarwal AN, et al. Non-invasive positive pressure ventilation in acute respiratory failure due to COPD vs. other causes: effectiveness and predictors of failure in a respiratory ICU in North India. Int I Chron Obstruct Pulmon Dis 2008;3:737-43. 